\title{
Rheumatoid arthritis and occupational therapy from the perspective of assisted technology
}

\author{
Artrita reumatoidă și terapia ocupațională din prisma tehnologiei asistate \\ Ana Maria Alexandra STĂNESCU ${ }^{1}$, Dumitru MATEI ${ }^{1}$, Alexandra TOTAN ${ }^{1,2}$, \\ Daniela MIRICESCU ${ }^{1,2}$, Daniela Oana TOADER ${ }^{1,3}$, Florica ŞANDRU ${ }^{1,4}$, \\ Constantin ȘTEFANI ${ }^{1}$, Camelia Cristina DIACONU ${ }^{1,5}$ \\ ${ }^{1}$ Universitatea de Medicină și Farmacie „Carol Davila“, București, România \\ ${ }^{2}$ Disciplina Biochimie, Facultatea de Medicină Dentară, \\ Universitatea de Medicină și Farmacie „Carol Davila“, București, România \\ ${ }^{3}$ Obstetrică, Ginecologie și Neonatologie, INSC „Alessandrescu-Rusescu“ - Clinica Polizu, \\ București, România \\ ${ }^{4}$ Spitalul Universitar de Urgență Elias, București, România \\ ${ }^{5}$ Spitalul Clinic de Urgență, București, România
}

\begin{abstract}
Assisted technology is used to improve or maintain the functional capacity of persons with disabilities. Rheumatoid arthritis is one of the conditions that affect the functional capacity of the individual, significantly impairing the quality of life. Currently, several assisted technologies are available, from the less complex ones, to the technologically complex ones that can be applied to patients with rheumatoid arthritis. The results of assisted technology in patients with rheumatoid arthritis represent a complex issue that requires a detailed approach.
\end{abstract}

Keywords: rheumatoid arthritis, assisted technology, occupational therapy

\section{REZUMAT}

Tehnologia asistată este utilizată pentru îmbunătățirea sau pentru menținerea capacității funcționale a persoanelor cu dizabilități. Artrita reumatoidă se numără printre afecțiunile care reduc capacitatea funcțională a individului, afectând în mod semnificativ calitatea vieții. La ora actuală, sunt disponibile mai multe tehnologii asistate, de la cele mai puțin complexe până la cele complexe din punct de vedere tehnologic, ce pot fi aplicate pacienților cu artrită reumatoidă. Rezultatele tehnologiei asistate $\hat{\imath} n$ artrita reumatoidă reprezintă o problemă complexă, ce necesită o abordare detaliată

Cuvinte cheie: artrită reumatoidă, tehnologie asistată, terapie ocupațională

\section{INTRODUCERE}

Artrita reumatoidă este o boală autoimună inflamatorie extrem de heterogenă, care afectează între $0,5 \%$ si $1 \%$ din populație (1). Sunt afectate mai des femeile decât bărbații, având debutul cu precădere între 45 și 65 de ani (2). Această boală se caracterizează prin inflamarea articulațiilor ce 
duce la durere și rigiditate, ulterior putându-se ajunge la distrugerea cartilajului. De multe ori, pacientul poate prezenta și alte boli genetice asociate inflamației articulare (3).

Controlul inflamației este primordial pentru a preveni debutul leziunilor structurale articulare (4). O dată apărute leziunile structurale, acestea vor duce la un handicap permanent (5). Abordarea artritei reumatoide trebuie să fie personalizată, atât din punctul de vedere al tratamentului farmacologic, cât și din punctul de vedere al fizioterapiei, al intervenției psihologice și al introducerii tehnologiei asistate.

Înțelegerea cauzelor și a mecanismelor de bază ale durerii la bolnavii cu artrită reumatoidă reprezintă o perspectivă în schimbare. Cu toate că medicamentele actuale au un potențial mare de reducere a inflamației și, în consecință, a durerii, prognosticul pe termen lung al durerii este încă adesea nefavorabil, chiar și după suprimarea inflamației. Durerea la nivelul și în jurul articulațiilor reprezintă un simptom-cheie. Durerea poate preceda efortul fizic sau trauma ușoară, în unele cazuri înaintea durerii pot să apară parestezii în jurul articulațiilor (6). Procesarea durerii de către sistemul nervos central poate menține și agrava durerea în cazul artritei reumatoide, fiind o țintă promițătoare pentru viitoarele tratamente. Pentru persoanele cu artrită reumatoidă care prezintă durere persistentă, pe lângă tratamentul antiinflamator sunt necesare și alte strategii care să vină în întâmpinarea dificultăților pacientului în activitățile zilnice cauzate de durere.

\section{INTRODUCERE ASUPRA TEHNOLOGIEI ASISTATE ÎN ARTRITA REUMATOIDĂ}

Tehnologia asistată reprezintă una dintre cele mai frecvente intervenții nonfarmacologice, nechirurgicale pentru bolnavii cu artrită reumatoidă, fiind o intervenție optimă pentru autoajutor la acești pacienți (7). Scopul tehnologiei asistate este de a permite bolnavilor să rămână independenți și să poată menține angajamentul în activitățile zilnice semnificative (8).

În acest context, termenul de tehnologie asistată este utilizat pentru echipament sau sistem fie că este achiziționat comercial de pe raft, modificat sau personalizat - care este utilizat pentru a crește, menține sau îmbunătăți capacitățile funcționale ale indivizilor cu dizabilități (9).

Conform clasificării produselor de asistență pentru persoanele cu dizabilități, tehnologia asistată include 11 categorii de produse. Dintre aceste categorii, cel mai frecvent, persoanele cu artrită reumatoidă utilizează tehnologii pentru îngrijire și protecție personală (ajutor pentru a se îmbrăca și pentru igiena personală), tehnologii pentru mobilitatea personală (scaune cu rotile, cârje), tehnologii pentru menaj (cuțite cu mânere ergonomice), mobilier specific și alte adaptări ale locuinței (scaune pentru duș și scaune de toaletă ridicate), tehnologii pentru manipularea produselor și bunurilor (ajutor pentru desfacerea conservelor) (10). O parte dintre aceste tehnologii sunt utilizate și de populația generală (de exemplu: periuța de dinți, deschizătoarele de conserve electrice), altele sunt utilizate numai de persoanele cu limitare funcțională sau dizabilități (de exemplu: scaunele cu rotile) (11).

\section{APLICATIII ALE TEHNOLOGIEI ASISTATE ÎN ARTRITA REUMATOIDĂ}

Utilizarea tehnologiei asistate este asociată cu severitatea bolii, cu durata lungă de boală și cu reducerea capacității funcționale $(10,12)$. Două treimi dintre toate persoanele cu artrită folosesc zilnic dispozitive de asistare (13).

Thyberg și colab. au arătat că bărbații cu artrită reumatoidă au folosit în medie trei dispozitive de tehnologie asistată, în timp ce femeile cu artrită reumatoidă au folosit în medie cinci dispozitive, iar dintre aceste dispozitive, cele mai utilizate au fost pentru alimentație (10). Un alt studiu a arătat că persoanele cu artrită reumatoidă severă folosesc în medie 10 dispozitive (14).

Tehnologia asistată are o natură complexă, fiind greu de evaluat din punctul de vedere al eficacității (15).

Dispozitivele de picurare. Averns și colab. au urmărit, la persoanele cu artrită reumatoidă, eficacitatea dispozitivului de picurare a picăturilor oculare. Acest tip de dispozitiv poate îmbunătăți capacitatea de stoarcere a picăturii, sporește controlul numărului de picături picurate și previne lezarea ochiului (flaconul nu mai poate atinge ochiul) (16).

Ortezele. Majoritatea persoanelor cu artrită reumatoidă vor dezvolta probleme ale picioarelor și ale gleznelor, acestea având un impact puternic asupra calității vieții (17). Studiile au demonstrat că durerea piciorului și dizabilitatea de mers sunt frecvent întâlnite la pacienții cu artrită reumatoidă (18). În urma analizării mersului la pacienții cu artrită reumatoidă, s-a evidențiat că aceștia merg mai lent, cu rotații anormale ale articulațiilor piciorului și modificări ale caracteristicilor de încărcare a presiunii plantare (19).

Ortezele pentru picior reprezintă o terapie adjuvantă nonfarmacologică recunoscută pentru în- 
grijirea medicală standard a pacienților cu artrită reumatoidă care prezintă probleme ale piciorului și gleznei. Ortezele sunt proiectate pentru a redistribui greutatea din anumite locuri, cum ar $\mathrm{fi}$ articulațiile dureroase, falangiene, metatarsiene, și pentru a controla postura arcului longitudinal medial în timpul mersului, prin controlul forțelor articulare (20).

Prescrierea ortezelor în artrita reumatoidă timpurie poate oferi o bună oportunitate pentru a atinge rezultate dezirabile, cu toate acestea, nu au existat studii controlate randomizate pentru a evalua eficacitatea lor în artrita reumatoidă precoce (21). Trei recenzii care investighează efectul ortezelor la pacienții cu artrită reumatoidă raportează un consens general potrivit căruia acestea sunt benefice; cu toate acestea, nu există informații despre ghidurile de prescripție medicală sau recomandările de tratament $(22,23,24)$.

Mănușile terapeutice. Funcția mâinii este definită drept "capacitatea de a folosi mâna în fiecare activitate" (25). Limitarea funcției mâinii la pacienții cu artrită reumatoidă este legată de calitatea mișcării articulare, precum și de forța musculară. Deși există diverse aspecte ale măsurilor funcției mâinii disponibile, este posibil ca nu toate aceste măsuri să evalueze și să reflecte în mod adecvat modificările funcției mâinii la toți pacienții (26).

Puterea de apucare a mâinii (în engleză „grip“) este esențială în multe activități zilnice și, din această cauză, este adesea folosită ca instrument de screening pentru evaluarea stării generale de sănătate a unei persoane (27). Puterea de apucare a mâinii poate fi evaluată măsurând cantitatea de forță statică pe care mâna o poate strânge în jurul unui dinamometru.
Mai multe studii au demonstrat că mănușile terapeutice au îmbunătățit rezistența la prindere a mâinilor $(28,29)$. Mănușa denumită Isotoner este compusă din amestec de fibre de nailon și elastan, în timp ce mănușa Futuro este compusă dintr-un amestec de fibre de lână și elastan. Deși ambele mănuși au îmbunătățit rezistența mâinilor la apucare, nu s-a putut demonstra superioritatea uneia dintre ele. Cercetătorii nu au putut identifica care mănușă este superioară și, în mod similar, care a fost mecanismul prin care mănușile influențează performanțele îmbunătățite ale mâinilor $(27,28)$.

Dexteritatea este definită drept capacitatea de a îndeplini o sarcină specifică, cum ar fi împingerea, apucarea sau tragerea unui obiect $(29,30)$. Inflamarea, rigiditatea și durerea în mână ar putea limita capacitatea unei persoane de a îndeplini chiar și o simplă sarcină de zi cu zi, cum ar fi aprinderea sau stingerea unei lumini, ceea ce, la rândul său, ar afecta calitatea vieții sale. Dexteritatea este îmbunătățită atunci când sunt purtate mănuși în comparație cu atunci când nu sunt purtate mănuși (31).

\section{CONCLUZII}

Deși opțiunile în ceea ce privește tehnologia asistată sunt foarte multe, studiile cu referire strictă la aplicabilitatea tehnologiei asistate în cadrul artritei reumatoide sunt foarte puține. Este o nevoie clară de cercetare amănunțită pentru a determina cu exactitate gradul de eficacitate a tehnologiei asistate în cadrul artritei reumatoide.

Conflict of interest: none declared
Financial support: none declared

\section{$\overline{\text { BIBLIOGRAFIE }}$}

1. Alamanos $Y$, Drosos AA. Epidemiology of adult rheumatoid arthritis. Autoimmun. Rev. 2005; 4:130-136.

2. Wikström I, Book C, Jacobsson LT. Difficulties in performing leisure activities among persons with newly diagnosed rheumatoid arthritis: A prospective controlled study. Rheumatology 2006; 45(9):1162-6.

3. Pratt AG, Isaacs JD. Seronegative rheumatoid arthritis: Pathogenetic and therapeutic aspects. Best Pract. Res. Clin. Rheumatol. 2014;28:651-659.

4. Anderson JJ, Wells G, Verhoeven AC, Felson DT. Factors predicting response to treatment in rheumatoid arthritis: The importance of disease duration. Arthritis Rheum. 2000;43:22-29.

5. Breedveld $F$. The value of early intervention in RA - A window of opportunity. Clin. Rheumatol. 2011;30:33-39.

6. Stack RJ, Tuyl LH, Sloots M et al. Symptom complexes in patients with seropositive arthralgia and in patients newly diagnosed with rheumatoid arthritis: A qualitative exploration of symptom development. Rheumatology (Oxford), 2014; 53(9):1646-1653.

7. Veitiene D, Tamulaitiene M. Comparison of self-management methods for osteoarthritis and rheumatoid arthritis. Journal of Rehabilitation Medicine 2005;37:58-60.
8. Wolfe T. Community resources and assistive devices for people with arthritis. Journal of Hand Therapy 2000; 13(2):184-92.

9. Assistive technology Act of 2004. Sec. 2 amendment to the assistive technology act of 1998. One Hundred and Eighth Congress of the United States of America.

10. Thyberg I, Hass UAM, Nordenskiold U et al. Survey of the use and effect of assistive devices in patients with early rheumatoid arthritis: A two-year follow up of women and men. Arthritis and Rheumatism 2004; 51(3):413-21.

11. Galumbeck MH, Buschbacher RM, Wilder $\mathrm{RP}$ et al. The Sit \& Stand chair. A 
revolutionary advance in adaptive seating systems. Journal of Long-Term Effects of Medical Implants 2004;14(6):535-43.

12. Shipham I, Pitout SJ. Rheumatoid arthritis: Hand function, activities of daily living, grip strength and essential assistive devices. Curationis 2003;26(3):98-106.

13. Rogers JC, Holm MB. Assistive technology device use in patients with rheumatic disease: A literature review. American Journal of Occupational Therapy 1992; 46(2):120-7.

14. Mann WC, Hurren D, Tomita M. Assistive devices used by home-based elderly with rheumatoid arthritis. American Journal of Occupational Therapy 1995;49(8):810-20.

15. McMillen AM, Söderberg S. Disabled persons' experience of dependence on assistive devices. Scandinavian Journal of Occupational Therapy 2002;9:176-83.

16. Averns H, Hall J, Webley M. Role of Opticare eye drop delivery system in patients with rheumatoid arthritis. The Journal of Rheumatology 1999; 26(12):2615-8.

17. Wickman AM, Pinzur MS, Kadanoff $R$ et al. Health-Related Quality of Life for Patients with Rheumatoid Arthritis Foot Involvement. Foot Ankle Int. 2004;25:19-26.

18. Grondal L, Tengstrand B, Nordmark B et al. The foot: Still the most important reason for walking incapacity in rheumatoid arthritis:
Distribution of symptomatic joints in 1,000 RA patients. Acta Orthopaedica. 2008; 79:257-261.

19. Baan H, Dubbeldam R, Nene AV, van de Laar MA. Gait analysis of the lower limb in patients with rheumatoid arthritis: A systematic review. Semin Arthritis Rheum. 2012;41:768-788.

20. Woodburn J, Helliwell PS, Barker S. Three-dimensional kinematics at the ankle joint complex in rheumatoid arthritis patients with painful valgus deformity of the rearfoot. Rheumatol. 2002;41:2356-2364.

21. Woodburn J, Hennessy K, Steultjens MP, et al. Looking through the "window of opportunity": Is there a new paradigm of podiatry care on the horizon in early rheumatoid arthritis? J Foot Ankle Res. 2010;3:8.

22. Clark H, Rome K, Plant M et al. A critical review of foot orthoses in the rheumatoid arthritic foot. Rheumatol. 2006;45:139-145.

23. Farrow SJ, Kingsley GH, Scott DL. Interventions for foot disease in rheumatoid arthritis: A systematic review. Arthritis Care Res. 2005;53:593-602.

24. Egan M, Brosseau L, Farmer M et al. Splints/orthoses in the treatment of rheumatoid arthritis. Physiotherapy. 2003; 89:141.

25. Dellhag B., Bjelle A. A five-year followup of hand function and activities of daily living in rheumatoid arthritis patients. Arthritis Care Res 1999;12: 33-41.

26. Jarus T., Poremba R. Hand function evaluation: A factor analysis study. Am J Occup Ther 1993;47: 439-443.

27. McKnight $P$, Kwoh C. Randomized, controlled trial of compression gloves in rheumatoid arthritis. Arthritis Care Res 1992; 5: 223-227.

28. Iftimie G, Stănescu AMA, lancu MA, et al. The importance of early arthritis in patients with reumatoid arthritis. J Mind Med Sci 2018;5(2):176-183.

29. Dianat I, Haslegrave C, Stedmon A. Methodology for evaluating gloves in relation to the effects on hand performance capabilities: A literature review. Ergonomics 2012;55: 1429-1451.

30. Popa AR, Vesa CM, Uivarosan D et al. Cross Sectional Study Regarding the Association Between Sweetened Beverages Intake, fast-food Products, Body Mass Index, Fasting Blood Glucose and Blood Pressure in the Young Adults from North-western Romania. Rev Chim (Bucharest) 2019; 70(1):156-160.

31. Culic D, Battaglia M, Wichman C, Schmid F. Efficacy of compression gloves in rheumatoid-arthritis. Am J Phys Med Rehab 1997;58: 278-284. 